\title{
Abortion Revisited: Toward an Understanding of the Nature of the Woman-Fetus Relationship
}

\author{
Vangie Bergum \\ University of Alberta
}

The abortion debate, as presented by the prolife and prochoice perspectives, should end, as it leads neither to solution nor to compromise. Rather, we need to reconsider how to understand the moral issues involved in this controversy for they touch on how we understand ourselves as a people, how we understand women's experience of pregnancy, and how such understanding affects what is considered important to us as a community. We need to move away from the "rights" perspective (from both fetal and maternal rights) in order to open other possibilities of understanding this issue. I propose that a more informed understanding of the nature of pregnancy itself can give a way to revisit this difficult and seemingly intractable moral controversy and begin a more fruitful dialogue.

\section{The Inadequacy of the Rights Approach for Abortion}

First, I suggest that, although there are certain appeals, the rights approach has a number of limitations. The rights approach takes a relatively simplistic, linear view of pregnancy, with the view of fetus and woman as distinct beings. It argues for personhood of the fetus in the prolife camp and right of privacy and against the obligation of women to use their bodies to support fetal life in the prochoice camp (Meilaender, 1989). The rights approach is simplistic in that it ignores the complexity of the woman-fetus relationship and supports the belief that taking sides for either the woman or the fetus will solve the problem.

Second, the notion that an unwanted pregnancy is a problem to be solved is also questionable. Undergirding the problem solving approach is a technological attitude, an attitude that values diagnosis of specific causes in order to provide intervention which may alter or correct the problem. Such an approach is appropriate and necessary for problems that are technical in nature (Braine \& Lesser, 1988). The unwanted pregnancy, however, is not such a situation. The unwanted pregnancy, as embodied by the woman, is a situation filled with personal physical 
changes, with emotional upheavals, and with practical concerns about the future-problems not easily solved.

Third, the rights approach which is the foundation for contractual thinking (thinking that holds self-interested or mutually disinterested individuals as constituting the paradigm of human relations) is inappropriate when considering the abortion situation. The emphasis on individual rights and "contractual" relations fails to recognize the experience of women (Held, 1988) and especially the experience of pregnancy. In fact, the experience of pregnancy for women gets lost in the abortion debate as currently formulated.

Pregnancy involves interaction between a woman (an independent person) and a fetus (a developing being). What a strange relationship: a relationship of intimate, involved participants, and a relationship that causes growth and change in both. Pregnancy is often seen primarily as a physical state so easily observed in the woman, and now observed through ultrasound in the fetus as well. To be pregnant means "carrying the developing fetus within the uterus," yet the word also means "creative," or "fraught with significance," which has its origin from the Latin praegnans "to give birth" (Morris, 1978, pp. $1033,1516)$. To give justice to the reality of the pregnancy experience as a human experience, we must not forget that being human means being part both of the natural world (physical) and the social world (communal) at the same time (Braine \& Lesser, 1988). That the pregnant body is easily objectified, analyzed, and treated is vividly illustrated in the technology of obstetrics. In contrast, the embodied social world of giving birth to a baby, which has to do with connection to the social community, is not so easily defined. The reality of giving birth, of creating new life, cannot be isolated and treated in a technical way and managed as a problem.

Pregnancy is often seen as being for the baby, yet pregnancy involves the growth of a woman who has thoughts and emotions-that is, she is not merely a vessel for the use of this other developing being. It is not insignificant that in a recent media report of the fetal heart surgery performed while in the uterus, there is no mention of the mother, just the "mother's womb" and the "mother's skin" (Heart Surgery, 1990). The separation of woman and fetus gives credibility to the description of the fetus as unborn patient and to the reference to the woman as vessel or human incubator, notions that are foreign to what the pregnant woman experiences. 
In an earlier study of women's experience of becoming mothers (Bergum, 1989), women described five thematic moments (see p. 13 for discussion of this term) that point to the nature of the change for themselves: the decision to have the child (before and after conception), the presence of the fetus in one's body, the pain of the separation from the baby, the gradual feeling of responsibility for the developing person, and the reality of having a child on one's mind (in some ways) forever. While the fetus grows and develops into human form (and it is important to remember that this cannot happen without the woman) so the woman changes into a mother (which cannot happen without a child). She changes not only in her body, but in her very nature, her way of seeing the world, her relationships, and her thinking. Through the experience of pregnancy which the woman lives out, she is transformed. So while it is true that through pregnancy a woman gives birth to a new human being, as baby, it is also true that a woman gives birth to a new way of living for herself, as mother.

The rights debate does not fit with a vision of woman-fetus bound together. The prolife view gets stuck on the fetus-forgetting the interaction with the woman. In the prolife position fetuses are often compared with infants, with the sick, with the weak, or with the senile - equating the fetus with the vulnerable person who is living independently of another body. The argument that compares abortion with other kinds of killing (such as in war, capital punishment, homicide, and mercy killings) uses the same kind of comparison. Yet fetuses are different: Fetuses are not independent beings. Until out of the womb, fetuses are tied in immeasurable ways to women.

The prochoice side of the debate centers on the rights of the woman to make decisions about her own body: She must not be forced to use her body to provide physical support for the fetus. Here again is the idea that the woman and fetus are distinct, that the woman houses the fetus for the sole purpose of providing for the other. Likewise, the analogy of likening carrying a fetus to organ donation is bizarre (Jung, 1988) and demonstrates little attention to the pregnancy experience. The fetus is not a body part like any other; the fetus is a uniquely different being that is, nevertheless, a part of the woman.

What is lost in the debate on abortion is the fact that the nature of pregnancy is such that the woman as well as the fetus is transformed, and this transformation of woman to mother is essential to an understanding of the need for a person-to-person relationship and a commitment to communal values that are necessary for us to live together. 


\section{The Nature of the Woman-Fetus Relationship}

The experience of carrying a fetus in one's body is hard to explain or even to describe. How does one experience being tied to another, a dependent being, in such an intimate, deep way? Women can and do talk about this experience-the experience of the embodied presence of the fetus and the experience of becoming present for the fetus, that is, being attentive to the new being as it develops. It is hard for rational minds to understand what is not easily or concretely ordered, such as this embodied experience of knowing the fetus to be a part of oneself and yet not oneself.

The exceptional intimacy of the woman-fetus interaction, this interrelationship, has been described by Rabuzzi (1988) as a "kind of interactive, two-in-one-self," where the selfhood of the woman becomes "motherselfhood" (pp. 43, 52). What is significant about the pregnancy experience is that it is the primordial experience that grounds humans in the many-leveled commitments to relationship, to family, to community, and to the environment in which we live. The woman-fetus relationship may seem fragile and unpredictable but, in the words of Sarah (1987), "is powerful and trustworthy, and is the foundation of the strongest bond between human beings, and the basis for all others [italics added]" (p. 69). The pregnancy experience, with its interconnection of woman and developing being, needs to be recognized and valued as the first and foremost experience of relationship for all humankind.

The possibility of the truth of such a primordial experience is evident in the unreflective words of a 12-year-old boy as he sat briefly on his mother's lap, "You know, this is my home." They had just been kibbutzing about how he used to be held in her lap-laughingly trying the different positions his preadolescent body could no longer comfortably fit-a body around which his mother could scarcely see. This boy was not talking about the home of the kitchen where they were playing. Rather, Sem was speaking of his first home, the body of his mother. The notion of home, where one can truly be oneself (see Bergum, 1989, pp. $47-49,75)$, is the first grounding and experience of a natural love, a love that is not sentimental or romantic, rather a love that allows the Other (the fetus) to grow and become the person (a child). This love (which may be seen as maternal, parental, and pedagogical) with its recognition of the fetus as a child for whom adults are responsible is vividly heard in the words of Jane following the birth of her daughter, "When she came out she was looking at both of us, very intelligently, almost as if she recognized us by our voices or something. It is just so over- 
whelming that you can't turn her down" (Bergum, 1989, p. 25). In this anecdote, the mother (and the father) want to do the right thing for the child; they want to respond to the helplessness of their child; they cannot turn her down.

Van Manen (1990) calls this spontaneous act,

a natural responsiveness: response-ability ... before we have a chance to sit back and reflect on whether or not we can accept this child, the child has already made us act. And luckily for humankind, this spontaneous needfulness to do the right thing usually is the right thing. (p. 146)

Outwardly, the right thing here is the daily activities of nourishing, bathing, cuddling, paying attention to the baby's needs, learning to recognize the cries, responding to cues of uncomfortableness of this new being. Inwardly, the woman (and the man, too) are transformed in their self-understanding; they start self-reflectively to reassess personal commitments and actions and wonder if they are doing the right thing (Bergum, 1989; van Manen, 1990).

The talk of women during pregnancy centers around this changing understanding of Self, "Who am I?" through the recognition of the fetus/baby as Other, "Who are You?" Over the nine months both of these themes take on new meanings for the women. As a woman begins to recognize the reality of the Other, the fetus/child, she is also attentive to her Self. In this experience it is not a detachment of Self to be attentive to an Other, rather it is an understanding of Self in relationship to the Other.

This is my body: The idea of baby. On first recognition of pregnancy the sense of the Other, the baby, is distant. Oh, yes, women say "I am going to have a baby," but that baby is just an idea, perhaps even a secret for a while, something that women may hold close to their hearts - "just to get used to the idea, and just sort out how we felt about it and adjust to it before we could share it with anybody else" (3: 1) 1 . "It was mine, a secret, it was something I had" (4: 1). Later one would share the fact of the pregnancy and the "going to have a baby" with others: husband, family, and friends. The baby, as an idea or as an abstraction, seemed more real for the mother than for the father: Women waited for the inner signs (movement, heartbeat) or the outer signs, the tighter skirts, and so forth, to make them realize that there indeed was a fetus/child present, whereas men could make the baby an object without waiting for signs from within themselves. For example, Pauline thought that in case of abnormalities discovered through the amniocentesis, Peter was 
"more comfortable with the notion of aborting than she would be" (10: 1), or the father could more easily talk to the baby whereas Glenda could not talk outloud to "a part of herself[rather] she would talk inwardly" (3: 1). Perhaps it is easier for men to "think concretely of a baby" while women are tied to experiencing the baby through their own bodies.

The idea of the child for the woman is caught in the focus on the self, on bodily changes that are often uncomfortable ("perhaps I am just sick"), a growing body that may feel like it is just fat, feeling vulnerability about being faced with overwhelming tasks, and the fear that I, myself, will be lost in the process and will not have control of my life. Pauline described it like this:

It's a world where you are not in charge any more. I'm a person who likes to be in control, and I like to be in charge, and I like to plan my life. And suddenly, because your placenta is pumping out all these hormones, it changes your life. You feel lousy and it's not like you can just, at least I couldn't, put on a stiff upper lip and carry on. It wasn't possible. And so an awful lot about what I had planned to do just had to go by the board. And that bothered me a lot. (10:1)

The focus of women during this early experience of pregnancy may be primarily on the self, "how am I feeling, how can I handle this new experience, I need friends and family to care for me, I fear losing myself, I fear losing control, and becoming dependent on others." The idea of the baby is found in the words "It is my body-Is there really a baby in there?" The woman has not yet begun, in a bodily way, to recognize the Other.

This is my body and my baby. The first encounter with the living other, the fetus, through hearing the heartbeat, seeing the ultrasound, feeling a movement ("I think once it started to really move I started to identify that it was a baby, not just something happening to me" 10:1.) prompts profound stirrings of recognition that there is someone else there. "Yes, now it is very real. Now I can think of the baby concretely. I have contact with this baby now where I didn't before. And now it is very real" (4: 2).

I had ultrasound quite early. I saw the heart beating and that was wonderful for me-although I had sore breasts and felt morning sickness, there was this nagging feeling that maybe 1 wasn't really pregnant after all, maybe there wasn't anything in there, maybe I had just made up those symptoms because I feel sorry for myself. It was so nice to see the embryo at that point and the heart beating. It made it more real. (10:1) 
The first encounter with these sounds of heartbeat and picture of the moving fetus bring women to a place of sensing someone other than themselves. It is real, that is, pregnancy is real, and the abstract baby is really there but not as an individual. "The baby is not a separate being but an extension of myself" (3: 1).

During this time there is talk about planning for the baby, planning on fixing a space in the home (not necessarily doing anything), about discussion with others, and discussion with partner about how this coming baby will change their relationship, that is, would it enhance or diminish the relationship as partners? The talking with others is significant it seems-the women talked about being let into a "secret" club, a club that consisted of women who had had children. Pauline talked about how Peter was also "allowed" into a "self-help group of men who were telling him what to expect, not only during the pregnancy, but after the birth" (10:1). This theorizing about the baby and what it will be like is part of this recognition of the pregnancy as preparing for a real child rather just an end in itself.

This is my body: This is my baby. Sylvie starts to the see the beginnings of the individual child when she describes the following event in her and her partner's life.

It definitely has a life of its own ... I had been reading on my side and then I turned on my back and the baby didn't like that position. I told Bob I could feel it tensing and doing things, and then it started moving and it had these deliberate movements... And as for me I knew that somebody else was in there, but it was a somebody who could decide when it wants to do something. All the other things were smaller pushes but this was a deliberate turning over and pushing and getting more space. It was definitely someone separate. Bob saw it too. (4:2)

The women guess about what the movements mean ("Sometimes I think he moves just to move, so I don't always interpret it as a sign that he's uncomfortable" 10:2) and think about the characteristics of their child. They find satisfaction in making sense of the behavior of the movements and responses of the fetus. The encounters with the fetus remind women that "before it was me but it's not any more, this is my baby, I really feel somebody" (3: 2). The coming to know the individual child continues to develop through play, through the movement, toward a more distinct recognition that this fetus/baby is a separate/separating being.

But sometimes when it's definitely a separate being is when it makes its presence known in an uncomfortable way. I talk to it 
after its been punching and making me very uncomfortable and then I realize it's a whole, separate, uncomfortable person in there because it is tossing and turning and poking me and I realize that that's the separate baby-but while it is in me, it's two of us, sharing this body, so I tell the baby to take mind of that (laughs) and share, it's not fair. (4: 3)

Here we hear the beginning attention to the Self and to the Other-that is, attention to both the needs of the Self (woman) and the needs of the Other (fetus). Willard (1988) would support this respect for two legitimate selves (woman and fetus) in relationship but recognizes that it forces the mother to live with the "ambiguity of judging rightness of her own response without reference to a ready-made rule" such as the "needs of the child always come first" (p. 242).

The talking to the baby, the shifting to make room (for example, "he reminds me to sit up"), the recognition that this is someone who is strong and vigorous, and one who can "make its own mind to do gymnastics and punch around" (4:3). Now, the baby is one that women hold in their arms and touch when a foot is pushing too hard, or who play and talk back and forth to each other. This talking to the baby, this give and take which begins before birth leads women to talk about the separation itself, to the meeting of the independent child. As the fetus/baby gets bigger, the woman can imagine pushing the baby out and begins to prepare for that separation. Some expect pain as a necessary part of that separation:

I think that using the pain as a mark of rite of passage, you know, that it's necessary. All the major events in your life you have to go through with a bit of pain. And I hope I feel some ... I don't want it that easy. (4: 2)

And I think the pain and the labor and what you go through really can affect mentally how I feel about the baby becoming a separate identity, apart from myself. I think the pain of labor, what is going to happen in labor, is going to be necessary for me to accept the separation. (3: 1)

Yet in the leaving of the woman's body, through the pain, the woman comes to see the child face to face. The inner relationship with the fetus/child ends. Now a new relationship begins. Or, perhaps more correctly, the relationship continues in a more direct person-to-person way.

\section{A Morality Based on Woman-Fetus Relationship}

In current Western thinking, we seem to have been so convinced that we need to base our moral decision making on 
universal principles and rules which hold individual rights and the social contract as primary, it may be difficult to see any other way. Held (1988) suggests that the mother-child relation, which occurs between the mothering person (who may be male or female) and the child, which develops through the care of the child, should be used as the primary relation from which to ground moral decision making. I am proposing that such a relation, what could be called the nurturing relation (ethical, pedagogical), has its roots in pregnancy. A society that holds nurturing relations as primary, that is, prior to contract relations, would base morality on "a responsive[ness] to actual, particular others in relations with us ... acting for particular others in actual contexts" (p. 133).

What would the world look like if we based morality decisions on the nurturing relation? How would a morality based on the nurturing relation help us make decisions about abortion? In considering the rightness or wrongness of abortion through a paradigm of nurturing relation rather than contract relation, importance would be placed on women's commitment to relationship with the fetus and the baby to whom they give life. Morality would be seen in commitment, in a woman's carefulness about entering, or continuing, a relationship that demands that she contribute the fertile, supportive ground from which to give life to the wanted and loved child. Such a morality would be centered on responsible and responsive choice, a choice which must be the woman's, not the doctor's and not the partner's. The choice must be the woman's not because of her right not to be a "vessel for a child," but because pregnancy, by its nature, moves a woman toward a powerful commitment to a relationship which will invade every part of her body, her thinking, that is, her life. Pregnancy is the foundation of a relationship that transforms both fetus and woman. The choice must be women's because the relationship is important to the developing fetus, to herself, and to the community into which the child is born.

Pregnancy as experience, then, cannot permit the conflict of woman versus fetus, life versus choice. Pregnancy is about woman and fetus; it is about life, and therefore about choice. If we take the pregnancy experience for what it is, with the fetus a part of the woman (not a separate entity), we cannot speak about women as vessels, containers, or as maternal environments; or of fetuses as babies, or products of conception, or unborn patients. If we take the pregnancy experience for what it is, women and their fetuses bound together, enmeshed in a social world (Rothman, 1989) and not just as a physical relationship (so easily managed by a technological attitude), we may 
be able to begin to understand the importance of choice for women as they move into, or out of, pregnancy.

\section{Note}

1. Ten women were asked to describe their experience of the fetus during the nine months of pregnancy. Some were interviewed three times, early, mid, and late pregnancy, and others only mid and late pregnancy. One women was interviewed shortly after an miscarriage in early pregnancy. Sylvie (4: Interview \#1, \#2, \#3), Pauline (10: Interview \#1, \#2, \#3), and Glenda (3: Interview \#1, \#2) most often do the speaking because of the clarity of their voices.

\section{References}

Bergum, V. (1989). Woman to mother: A transformation. Granby, MA: Bergin \& Garvey.

Braine, D., \& Lesser, H. (1988). Ethics, technology and medicine. Aldershot, UK: Avebury.

Heart surgery performed in the womb. (1990, February 1). Edmonton Journal.

Held, V. (1988). Non-contractual society: A feminist view. Canadian Journal of Philosophy, 13, 111-137.

Jung, P.B. (1988). Abortion and organ donation: Christian reflections of bodily life support. Journal of Religious Ethics, 16(2), 273-305.

Meilaender, G. (1989). Abortion: The right to an argument. The Hastings Center Report, 19(6), 14-16.

Morris, W. (Ed.). (1978). The American heritage dictionary. Boston, MA: Houghton Mifflin.

Rabuzzi, K.A. (1988). Motherself: A mythic analysis of motherhood. Bloomington, IN: Indiana University Press.

Rothman, B.K. (1989). Recreating motherhood: Ideology and technology in patriarchal society. New York: Norton.

Sarah, R. (1987). Power, certainty, and the fear of death. Women \& Health, 13(1-2), 59-72.

van Manen, M. (1990). Researching lived experience: Human science for an action sensitive pedagogy. London, $\mathrm{ON}$ : Althouse.

Willard, A. (1988). Cultural scripts for mothering. In C. Gilligan, J. Ward, \& J. Taylor (Eds.), Mapping the moral domain (pp. 225-243). Cambridge, MA: Harvard University Press. 